East African Medical Journal Vol. 87 No. 6 June 2010

CHILD MALNUTRITION IN TIGRAY, NORTHERN ETHIOPIA

A. Mulugeta, PhD, Assistant Professor, Department of Public Health, Mekelle University, Ethiopia, F. Hagos, PhD, Researcher, International Water Management Institute, G. Kruseman, PhD, Researcher, V. Linderhof, PhD, Researcher, Agricultural Economics Research Institute, Wageningen University and Research Center, The Hague, The Netherlands, B. Stoeker, PhD, Regents Professor, Department of Nutritional Sciences, Oklahoma State University, Stillwater, OK, 74078, USA, Z. Abraha, MS, Lecturer, Department of Land Resources and Environmental Protection, M. Yohannes, PhD, Department of Medicine and G. G. Samuel, PhD, Assistant Professor, Department of Land Resources and Environmental Protection, Mekelle University, Ethiopia

Request for reprints to: Dr. A. Mulugeta, Department of Public Health, Mekelle University, Ethiopia

\title{
CHILD MALNUTRITION IN TIGRAY, NORTHERN ETHIOPIA
}

\author{
A. MULUGETA, F. HAGOS, G. KRUSEMAN, V. LINDERHOF, B. STOECKER, Z. ABRAHA, \\ M. YOHANNES and G. G. SAMUEL
}

\begin{abstract}
Objective: Estimate levels of and identify factors contributing to child malnutrition in Tigray, Northern Ethiopia.

Design: Cross-sectional survey.

Setting: Rural communities from four zones of Tigray.

Subjects: Three hundred and eighteen under five children representing 587 randomly selected households were included.

Results: Among the children surveyed, $46.9 \%, 33.0 \%$ and $11.6 \%$ were stunted, underweight and wasted, respectively. Older children were more likely to be undernourished. Stunting increases from $16 \%$ in the second half of the first year to $53 \%$ in children 24 months and older. Similarly, underweight increases from $10 \%$ in the first six months to $36.5 \%$ in children aged 24 months and older. A very high proportion of the mothers $(80 \%)$ initiated feeding of newborns with pre-lacteal feeds primarily butter or water. Family foods and cereal-based porridge were the main complementary foods after six months. Child age, maternal anthropometric characteristics, inadequate complementary foods, the use of prelacteal feeds and area of residence were the main contributing factors to child undernutrition.

Conclusion: Undernutrition gets worse as the children grow older. The energy and nutrient density of the complementary foods are low as the foods were prepared from a limited number of local staple cereals without the addition of sugar, fat/oil or animal products. More importantly, these foods are diluted with water to reduce their viscosity. This makes the quality and quantity of the foods insufficient to prevent stunting and underweight. Promotion of traditional household technologies such as germination and fermentation may be affordable measures to improve the quality of the complementary foods. Thus, sustained nutrition education programmes focusing on appropriate complementary feeding practices are recommended.
\end{abstract}

\section{INTRODUCTION}

Of the nearly 1.9 billion children in the developing world, $31 \%$ are stunted $(1,2)$. Despite the continued progressin the developing countries, itisstill predicted that there will be 128-155 million underweight children by the year 2020 with $35 \%$ of these children to be from sub-Saharan Africa (3).

The most important documented forms of malnutrition in Ethiopia are protein energy malnutrition and vitamin $\mathrm{A}$, iodine, iron and zinc deficiencies (4-8). Child malnutrition in Ethiopia constitutes a particularly daunting challenge as the country had a 17\% under five mortality rate in 2001 of which an estimated $57 \%$ was linked to severe and mild to moderate malnutrition (9). The most recent national data showed that $41 \%, 42 \%$ and $11.6 \%$ of the under five children were below -2 Z-scores for height for age, weight for age and weight for height, respectively (10). These figures are among the highest in the world (2).

High rates of malnutrition can be attributed to both intrauterine growth retardation and post natal growth faltering (11). Though there is a lack of agreement about the relative importance of the factors affecting the nutritional status of children (9), 
the postnatal growth faltering in Ethiopia is largely caused by high rates of infection, limited household food availability, and poor infant feeding practices leading to inadequate energy and nutrient intakes $(4,12)$.

Linear growth deficit is an important indicator of nutritional deficiency in children less than five years of age. The deficit begins in the first $4-6$ months of postpartum life and is accentuated throughout the first three years of life. Between 3 and 5 years of age, the rate of decline decreases, but in many cases, compromised stature persists throughout the individual's life (13). Although many questions remain concerning the mechanism and magnitude of effects, there is now considerable evidence that malnutrition has effects on physical growth, morbidity, mortality, cognitive development, reproduction, physical work capacity and risks for several adulthood chronic diseases $(14,15)$.

\section{MATERIALS AND METHODS}

Socio-demographic information: A household questionnaire was used to collect socio-demographic information by interviewing mothers. Either the key caregiver to the child or the father was interviewed when the mother was absent during data collection. A pilot survey was conducted in a host community and problems highlighted during the pilot survey were corrected before the start of the actual survey.

Study subjects: This cross sectional study was conducted between October 2004 and January 2005 in 318 under five children representing 587 randomly selected households from Central, Eastern, Northwestern and Southern zones of Tigray.

Anthropometry: Age, sex, weight and height were recorded. Height and weight were measured to the nearest $0.1 \mathrm{~cm}$ and $0.1 \mathrm{~kg}$, respectively. For children under two years of age, recumbent length measurement was taken. Each subject was weighed with minimum clothing and no foot wear. Age of each child was collected from the mother and counter checked using vaccination cards, baptismal certificates or other forms of informal recording. The 2006 WHO Anthro software were used to calculate height-for-age (HAZ), weight-for-age (WAZ) and weight-for-height (WHZ) Z-scores. Children with HAZ, WAZ and WHZ below -2 were characterised as stunted, underweight and wasted, respectively. These variables were considered as the dependent variables during statistical analysis.

Ethical considerations: Approvals from local authorities and community leaders' consent were secured before starting data collection in a given community and parental consents were obtained before starting interviews or taking body measurements. Ethical clearance to use the de- identified data was obtained from the Institutional Review Board (IRB) of Oklahoma State University, USA.

Quality control: The interviewers were trained to standardise the questionnaire administration and anthropometric measurements. All the interviewers were able to communicate in the local language. Daily close supervision (spot checks, re-interviewing and thorough scrutiny of filled-in questionnaires) was made by the field supervisors deployed with the data collectors. At the end of every community level data collection, meetings were held between data collectors, supervisors and the research team to discuss practical problems and issues of major concern. Subjects were re-interviewed when item non responses were encountered.

Statistical analysis: Data were analysed using the Statistical Analysis System Software (SAS, version 9.1). Statistical analyses included descriptive statistics, student t-test, analysis of variance (ANOVA) and multiple regressions. Statistical significance was set at $\mathrm{p}<0.05$.

\section{RESULTS}

Indicators of child malnutrition were assessed against potential independent variables such as maternal characteristics, access to social services, complementary foods, breastfeeding practices, household and community characteristics.

All the households were from rural areas and made their living by farming and animal husbandry. Most $(90 \%)$ of the mothers were illiterate. About $70 \%$ reported that they had access to safe drinking water and $84 \%$ of the households had no latrine. Health service utilisation for delivery was minimal as $95 \%$ of the mothers reported that they gave birth at home but $80 \%$ of mothers reported that they had access to family planning services. Almost all (96\%) of the mothers were married and $74 \%$ first gave birth at the age of 20 years or less. The mean age of maternal marriage and first birth in the study area were 14.7 and 18 years, respectively. Surprisingly, the youngest marriage age reported was seven years. More than half $(54.5 \%)$ of the mothers were nutritionally deprived based on their body mass index (BMI < 18.5).

Only one-fifth of the mothers started breast feeding immediately after birth but $80 \%$ started within an hour of birth. More than $88 \%$ of the mothers breastfed their children until two years of age and $25 \%$ continued breastfeeding for more 
than three years. An early introduction of other non breast milk fluids was very common in the study communities. More than $80 \%$ of the mothers initiated feeding their children with non breast milk pre-lacteal foods. The commonly used prelacteal foods were butter $(46.7 \%)$, sugar dissolved in water $(15.1 \%)$ and plain water $(14.5 \%)$. Family foods and cereal based porridge were the most common complementary foods.

Of the 318 under five children, $160(50.3 \%)$ were females and $158(49.7 \%)$ were males. The mean age was 32 months. The mean HAZ, WAZ and WHZ scores were -1.76 (95\% CI: -1.97 to -1.57$)$, -1.43 (95\% CI: -1.57 to -1.28$)$ and -0.59 (95\% CI: -0.73 to 0.44$)$, respectively (Table 1$)$. None of the mothers were less than $145 \mathrm{~cm}$ in height. However, $48 \%$ of them were less than $45 \mathrm{~kg}$ and more than half (55\%) of the mothers suffer from chronic energy deficiency, BMI $<18.5$ (Table 2).

\section{Table 1}

Anthropometric and demographic information of children $(n=316-318)$

\begin{tabular}{lll}
\hline Variable & Mean $(\mathrm{sd})$ \\
\hline Child age (months) & 32.0 & $(14.4)$ \\
Child weight $(\mathrm{kg})$ & 11.1 & $(2.5)$ \\
Child height $(\mathrm{cm})$ & 84.7 & $(10.27)$ \\
HAZ & $-1.77(1.8)$ \\
WAZ & $-1.43(1.3)$ \\
WHZ & $-0.59(1.3)$ \\
\hline
\end{tabular}

Table 2

Anthropometric and demographic information of mothers $(n=306$ - 314)

\begin{tabular}{ll}
\hline Variable & Mean $(\mathrm{sd})$ \\
\hline Maternal age (years) & $33.2(8.2)$ \\
Maternal weight $(\mathrm{kg})$ & $45.7(5.5)$ \\
Maternal height $(\mathrm{cm})$ & $156.7(5.9)$ \\
Maternal BMI $\left(\mathrm{kg} / \mathrm{m}^{2}\right)$ & $18.6(2.0)$ \\
Age at first marriage (years) & $14.7(2.7)$ \\
Age at first birth (years) & $18.2(2.3)$ \\
\hline
\end{tabular}

The cross-sectional prevalence of stunting, underweight and wasting of children was $46.9 \%, 33.0 \%$ and $11.6 \%$, respectively. Compared with the $2006 \mathrm{WHO}$ standards, the distribution of the z-scores of these children is shifted to the left (Figures 1 and 2).
Figure 1

Left shifting of the distribution of weight-for-age $z$ scores of study children and 2006 WHO standard population

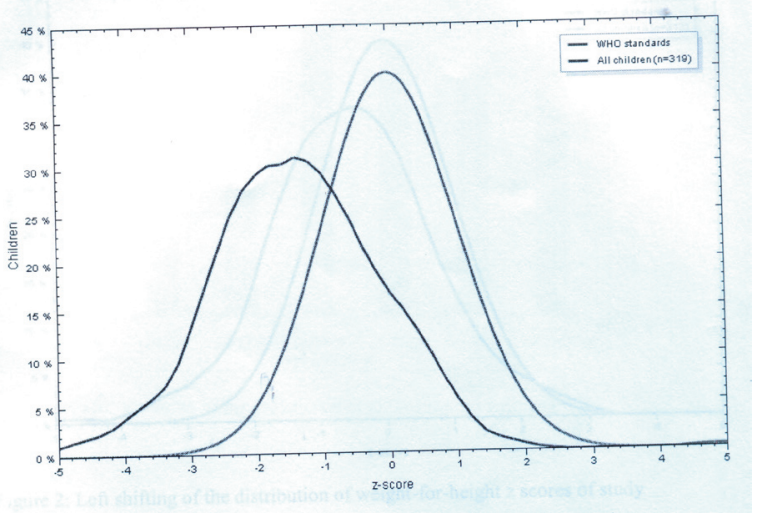

Figure 2

Left shifting of the distribution of weight-for-height $z$ scores of study children and 2006 WHO standard population

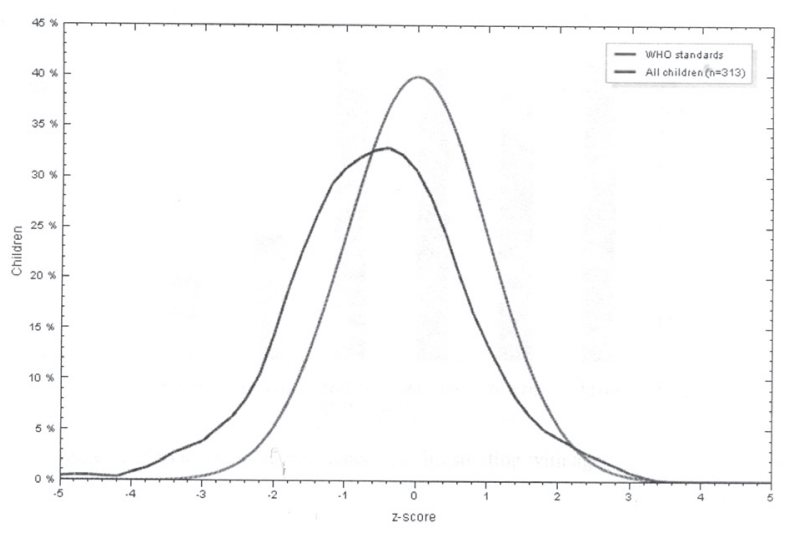

The prevalence of stunting increased from $0 \%$ in children younger than six months, to $29 \%$ in children between 12 and 17 months and to 55.8\% in children older than four years (Figure 3).

Figure 3

Variation in the prevalence of child stunting with age

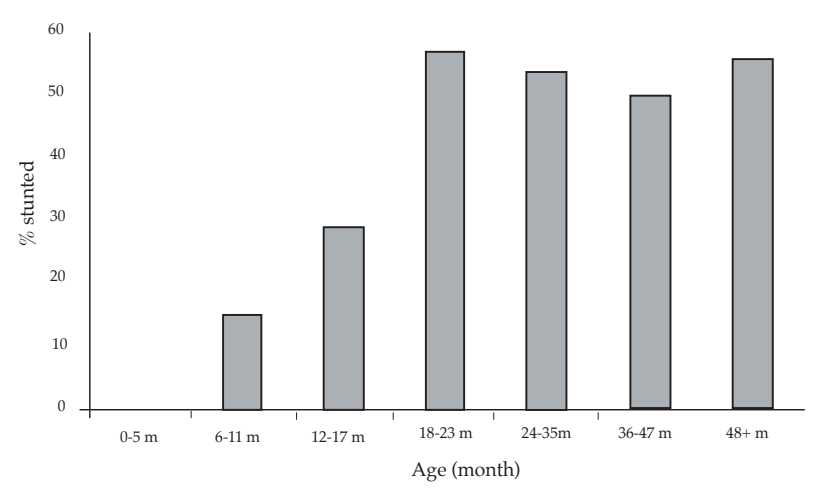


There were no significant differences between the height-for-age $(p=0.4108)$, weight-for-age $(\mathrm{p}=0.3886)$ and weight-for-height $(\mathrm{p}=0.6229) \mathrm{z}$-scores for male and female children. Likewise there was no significant difference in stunting $(\mathrm{p}=0.0782)$, underweight $(\mathrm{p}=0.0913)$ and wasting $(\mathrm{p}=0.4229)$ between children from households with and without home gardening.

The prevalence of chronic child malnutrition (stunting) was $35.7 \%, 47.8 \%, 52.3 \%$ and $55.6 \%$ in the northwestern, eastern, central and southern zones, respectively. Children from the central zone had significantly lower mean WHZ scores $(p=0.0002)$ and children from the north western zone had significantly higher mean WAZ scores than those from central and southern zones $(\mathrm{p}=0.0023)$. The characteristics which significantly affected the child height and weight Z-scores are presented in Table 3.

Based on the stepwise multiple regression analysis, the best predictors for long term undernutrition were child age, maternal height and complementary foods. The predictors of child weightfor-age z-scores were the child age, maternal weight, complementary foods and place of residence (zone) and that of wasting were maternal height, maternal BMI and place of residence. Results of the multiple regression analysis for variables significantly linked to child undernutrition are shown in Table 4.

Table 3

Effect of age, maternal BMI, complementary foods and residence zone on height-for-age, weight-for-age and weightfor-height $z$ scores $(n=318)$

\begin{tabular}{|c|c|c|c|}
\hline & $\begin{array}{l}\text { HAZ } \\
\text { mean (sd) }\end{array}$ & $\begin{array}{l}\text { WAZ } \\
\text { mean (sd) }\end{array}$ & $\begin{array}{l}\text { WHZ } \\
\text { mean (sd) }\end{array}$ \\
\hline \multicolumn{4}{|l|}{ Age (months) } \\
\hline $0-5$ & $0.63 \quad(2.07)^{a}$ & $0.08 \quad(2.05)^{a}$ & $-0.36(1.53)$ \\
\hline $6-11$ & $-1.21(1.03) b c$ & $-0.86(1.28)^{\mathrm{b}}$ & $-0.31(1.74)$ \\
\hline $12-23$ & $-0.92(2.40)^{\mathrm{b}}$ & $-1.10(1.48)^{\mathrm{b}}$ & $-0.84(1.85)$ \\
\hline$\geq 24$ & $-2.07(1.55)^{\mathrm{c}}$ & $-1.60(1.18)^{\mathrm{b}}$ & $-0.57(1.15)$ \\
\hline $\mathrm{P}$-value & $<0.0001$ & $<0.0001$ & 0.4253 \\
\hline \multicolumn{4}{|l|}{ Maternal BMI } \\
\hline$<16.5$ & $-0.94(2.18)^{a}$ & $-1.30(1.22)$ & $-1.05(1.43)^{a}$ \\
\hline $16.5-18.49$ & $-1.95(1.67)^{b}$ & $-1.59(1.30)$ & $-0.64(1.23)^{b}$ \\
\hline$\geq 18.5$ & $-1.88(1.69)^{\mathrm{b}}$ & $-1.33(1.35)$ & $-0.39(1.32)^{b}$ \\
\hline P-value & 0.0029 & 0.2077 & 0.0096 \\
\hline \multicolumn{4}{|c|}{ Complementary foods } \\
\hline No & $-2.25(1.69)^{a}$ & $-1.72(1.35)^{a}$ & $-0.56(1.27)$ \\
\hline Yes & $-1.52(0.11)^{\mathrm{b}}$ & $-1.28 \quad(1.27)^{\mathrm{b}}$ & $-0.60(1.34)$ \\
\hline P-value & 0.0006 & 0.0051 & 0.7763 \\
\hline \multicolumn{4}{|l|}{ Residence/zone } \\
\hline Central & $-1.79(2.24)^{a b}$ & $-1.87(1.23)^{\mathrm{c}}$ & $-1.17(1.34)^{\mathrm{a}}$ \\
\hline Eastern & $-1.80(1.59)^{\mathrm{ab}}$ & $-1.25(1.36)^{\mathrm{ab}}$ & $-0.29(1.21)^{b}$ \\
\hline North Western & $-1.42(1.42)^{\mathrm{a}}$ & $-118(1.21)^{\mathrm{a}}$ & $-0.60(1.41)^{b}$ \\
\hline Southern & $-2.22(2.00)^{\mathrm{b}}$ & $-1.66(1.32)^{\mathrm{bc}}$ & $-0.49(1.15)^{b}$ \\
\hline P-value & 0.0803 & 0.0023 & 0.0002 \\
\hline
\end{tabular}

*different letters show significance at $\mathrm{p}<0.05$ and values which share a common superscript are not significantly different from each other at $\mathrm{p}<0.05$. 
Table 4

Predictors of child height-for-age and weight-for-age z-scores $(n=318)$

\begin{tabular}{|c|c|c|c|}
\hline & Estimate & s.e. & P-value \\
\hline \multicolumn{4}{|c|}{ Predictors of height-for-age z-scores } \\
\hline Intercept & - 12.5411 & 2.4976 & $<0.0001$ \\
\hline Child age & -0.0390 & 0.0065 & $<0.0001$ \\
\hline Maternal height & 0.0767 & 0.0158 & $<0.0001$ \\
\hline \multicolumn{4}{|c|}{ Complementary foods* } \\
\hline Intercept & -1.5238 & 0.1213 & $<0.0001$ \\
\hline No & -0.7298 & 0.2094 & 0.0006 \\
\hline \multicolumn{4}{|c|}{ Predictors of weight- for-age z-scores } \\
\hline Intercept & -2.0855 & 0.6287 & 0.0010 \\
\hline Child age & -0.0242 & 0.0049 & $<0.0001$ \\
\hline Maternal weight & 0.0311 & 0.0133 & 0.0198 \\
\hline \multicolumn{4}{|c|}{ Complementary foods* } \\
\hline Intercept & -1.2821 & 0.0895 & $<0.0001$ \\
\hline No & -0.4331 & 0.1536 & 0.0051 \\
\hline \multicolumn{4}{|l|}{ Residence/zone* } \\
\hline Intercept & -1.6622 & 0.1752 & $<0.0001$ \\
\hline North West & 0.4789 & 0.2246 & 0.0338 \\
\hline \multicolumn{4}{|c|}{ Predictors of weight- for-height $\mathrm{z}$-scores } \\
\hline Intercept & 1.9001 & 2.2320 & 0.3953 \\
\hline Maternal height & -0.0295 & 0.0127 & 0.0214 \\
\hline Maternal BMI & 0.1139 & 0.0383 & 0.0032 \\
\hline \multicolumn{4}{|l|}{ Residence/zone* } \\
\hline Intercept & -0.4937 & 0.1746 & 0.0050 \\
\hline Central & -0.6735 & 0.2362 & 0.0046 \\
\hline
\end{tabular}

*analysed as dummy variables using 'Yes' and 'Southern zone' as references for complementary foods and place of residence, respectively

Taller mothers had taller children. Children from families that used cereal-based complementary foods had statistically higher HAZ ( $\mathrm{p}=0.0006)$ and WAZ $(\mathrm{p}=0.0051)$ scores than those who did not. Child nutritional status became worse with age. Contrary to our expectations, maternal characteristics such as education level and access to family planning services and household characteristics such as access to safe drinking water and latrine were not significantly associated with child stunting and underweight.

\section{DISCUSSION}

In contrast to other studies (9), where boys had significantly worse nutritional status than girls, no association between gender and nutritional status was observed in our study. Complementary foods were the most easily modifiable predictors of child nutritional status in the study communities. Children who received complementary foods from cereals had a better nutritional status than those who did not.

The distribution of the three anthropometric indices of the study population was shifted to the left compared to the $2006 \mathrm{WHO}$ standard population, indicating that undernutrition was serious in underfive children from the study communities. Child malnutrition increased with age. It appears that both chronic and acute child malnutrition, develop during the weaning period and rise sharply thereafter. The retardation of growth, which commences in the first year of life, suggests problems associated with child feeding practices, nutrient inadequacy of the complementary foods and the direct contact of children with the soil as a result of crawling away from their caregivers. Studies have shown that long-term breast feeding adversely affects infant appetite and growth (16). Breastfeeding beyond 12 months was very common in these communities and such breast feeding practices might reduce consumption of non breast milk foods and lower energy intake in children. 
Moreover, the commonly used complementary foods were cereal based prepared by mixing two or more flours of barley, teff, wheat, maize or sorghum. These foods are diluted with water to reduce their viscosity and are often unsafe because of unsanitary preparation and storage practices. The total amount of food consumed by young children is affected by feeding frequency, the energy density of the diet, physico- chemical properties of the food and the child's appetite (17-19). There is a trade off between intake of complementary foods and intake of breast milk. Though the study did not collect information on the nutrient density of the complementary foods, the foods were introduced late and were inadequate in quantity and quality.

Significant differences in nutritional status were observed amongst the different zones. Southern zone followed by the central zone have the highest rate of long term undernutrition. However, the prevalence of short term undernutrition as evidenced by wasting was higher in central and northwestern zones. The central zone, where both long term and short term undernutrition were prevalent, is characterised by the highest population density causing small land holdings and compromising the household food security. Such a difference in prevalence of child undernutrition between the zones emphasizes the importance of environmental factors.

A study by Waters et al (20) show that maternal education has prominent effects on nutritional status of children. However, in our study, most mothers were illiterate and maternal education was not strongly associated with child nutritional status. The impact of maternal education is not only through its effect on nutrition but also through additional income and the mother's ability to make better decisions for herself and her children. The rural mothers included in this study had few opportunities to earn additional income or to make many changes in the child's food intake and hence the lack of significant association between maternal education and child nutritional status should not be a surprise. Similarly, we found no statistically significant association between the nutritional status of children and availability of home gardening in the households.

Plausible reasons for such observation include: first, the vegetables in the households might be displacing other staple energy foods. Secondly, the mother's involvement in home gardening might have a negative effect on the children's nutritional status by reducing infants' access to breastfeeding, or to use breastfeeding as a substitute for a regular meal thereby extending duration of breast feeding beyond two years of age.

Third, childrenmay be disadvantaged either from being left alone or from exposure to harsh climatic conditions when accompanying their mothers, contributing to child weakness and vulnerability to infections. And finally, the vegetables from the home gardening might not be used for household consumption but for income generation destined for purposes other than provision of sufficient food to the household and the children.

The results of our study also demonstrate that there was no significant association between access to safe drinking water and child nutritional status. However, there was significant interaction between access to safe drinking water and use of complementary foods $(p=0.0129)$. This might be due to the fact that, many mothers are aware of the general importance of clean water sources but not about what characterises clean water.

Unless, the clean water from the source is utilised and stored under hygienic conditions, it may be contaminated very easily and serve as a vehicle for infections. This situation can further be exacerbated by the absence of latrine facilities in the majority of the households.

Practices of continuing breast feeding were to the international and country standards as $88 \%$ of the mothers breast fed their children for at least two years. However, one in ten of the children received pre-lacteal feeds immediately after birth. The practice of early start of feeding other liquids / foods in these study communities should be discouraged for many reasons including the potential risk of infection and the fact that flow of breast milk is not well stimulated when the infant's hunger and thirst are satisfied by other liquids.

In conclusion, our data demonstrates that lack of complementary foods was important predictor of child undernutrition and that chronicundernutrition was a publichealth problem in the study communities. The rate of chronic undernutrition becomes more apparent as children grow older. The energy and nutrient density of the family and complementary foods were low as they are prepared from a limited number of local staple cereals and legumes without the addition of sugar, fat or animal products and hence were insufficient to prevent child undernutrition.

We recommend sustained nutrition education programmes to adolescent girls, mothers and elderly women focusing on appropriate child feeding practices and promotion of traditional household technologies such as germination and fermentation to improve the quality of the complementary foods.

\section{ACKNOWLEDGEMENTS}

The study was supported by the Netherlands Development Cooperation through the Poverty Reduction and Environmental Management (PREM), Institute of Environmental Studies (IVM), Vrije Universiteit, Amsterdam, The Netherlands, 
Oklahoma State University, USA, and Mekelle University, Ethiopia. Wethank thelocal administrators and community leaders for their support during the survey.

\section{REFERENCES}

1. The State of the World's Children, AUNICEF Report: Childhood under threat. 2005; 1 - 151.

2. The State of the World's Children. AUNICEF Report: Excluded and invisible. 2006; 112-115.

3. Underwood, B.A. Health and nutrition in women, infants and children: Overview of the global situation and the Asian Enigma. Nutr. Rev. 2002; 60: S7-S13.

4. Getahun, Z., Urga, K., Ganebo, T. and Nigatu, A. Review of the status of malnutrition and trends in Ethiopia. Ethiop. J. Hlth. Dev. 2001; 15: 55-74.

5. Umeta, M., West, C.E. Haidar, J., et al. Zinc supplementation and stunted infants in Ethiopia: a randomized controlled trial. Lancet. 2000; 355: 2021-2026.

6. Taffesse, Y., Fisseha, T., Umeta, M., Haidar, J. and Teka, W. Vitamin A deficiency: a serious threat in Dodota district in central Ethiopia. East Afr. Med. J. 1996; 73:303-307.

7. Cherinet, A. and Urga, K. Determinants of iodine deficiency in school children in different regions of Ethiopia. East Afr. Med. J. 2000; 77: 121-122.

8. Negalign, B. Kifle, W. and Meselle, B. Endemic goitre in school children in southern Ethiopia. Ethiop. J. Hlth. Dev. 2004; 18: 175-178.

9. Alemu, M., Nicola, J. and Bekele, T. Tackling child malnutrition in Ethiopia: Do the sustainable development poverty reduction program'sunderlying policy assumptions reflect local realities? Young Lives, An International Study of Childhood Poverty, Working paper No. 19: 2005.

10. Central Statistics Authority, Ethiopia Demographic and Health Survey Preliminary Report. 2005; 20-24.
11. Bhandari, N., Mazumder, S., Bahl, R., et al. An educational intervention to promote appropriate complementary feeding practices and physical growth in infants and young children in rural Haryana India. J. Nutr. 2004; 134: 2342-2348.

12. Umeta, M., West, C.E., Verhoef, H., Haidar, J. and Hauvtast, J.G.A.J. Factors associated with stunting in infants aged 5 - 11 months in the Dodota-Sire district, rural Ethiopia. J. Nutr. 2003: 133: 1064-1069.

13. Assis, A., Prado, M., Barreto, M., et al. Childhood stunting in Northeast Brazil: the role of schistosoma mansoni infection and inadequate dietary intake. Eur. J. Clin. Nutr. 2004; 58: 1022-1029.

14. Pallelier, D. L. and Frongillo, E. A. Changes in child survival are strongly associated with changes in malnutrition in developing countries. J. Nutr. 2003; 133: 107-119.

15. Ricci, J.A. and Becker, S. Risk factors for wasting and stunting among children in Metro Cebu, Philippines. Am. J. Clin. Nutr. 1996; 63: 966-975.

16. World Health Organization (WHO/NUT/98.1). Complementary feeding of children in developing countries: a review of current scientific knowledge. 1998; 41-44.

17. Brown, K.H., Sanchez-Grinan, M., Perez, F., et al. Effects of dietary energy density and feeding frequency on total daily energy intakes of recovering malnourished children. Am. J. Clin. Nutr. 1995; 62: 13-18.

18. Bennett, V.A., Morales, E., Gonzalez, J., et al. Effects of dietary viscosity and energy density on total daily energy consumption by young Peruvian children. Am. J. Clin. Nutr. 1999; 70: 285-291.

19. Gibson, R.S., Ferguson, E. and Lehrfeld, J. Complementary foods for infant feeding in developing countries: their nutrient adequacy and improvement. Eur. J. Clin. Nutr. 1998; 52: 764-770.

20. Waters, H., Saadah, F., Surbakti, S. and Heywood, P. Weight-for-age malnutrition in Indonesian children, 1992-1999. Int. J. Epidemiol. 2004; 33: 589-595. 